\title{
Consumistas ou sujeitos de suas existências? Estratégias e táticas de juventudes da escola pública na cultura do consumo
}

\author{
Consumers or subjects of their existence? \\ Strategies and tactics of state school youth in consumer culture
}

\author{
Rodrigo Cerqueira do Nascimento BORBA ${ }^{1}$ \\ Matheus Sampaio Favrat dos SANTOS 2 \\ Maria Jacqueline Girão Soares de LIMA $^{3}$
}

\begin{abstract}
Resumo
O presente trabalho analisa representaçôes produzidas por jovens estudantes de uma escola pública carioca, compartilhadas em um grupo focal sobre suas práticas de consumo. Inspirados em Michel De Certeau, operamos com as noções de "estratégia" e "tática" para compreender as interaçóes das juventudes com suas realidades socioculturais, e, a partir delas, as açôes criadas para a satisfação de desejos de consumo ou subversão dos dispositivos sociais de fomento ao mesmo. Por fim, a partir das narrativas dos sujeitos da pesquisa, indiciamos e debatemos elementos-chave para a compreensão de suas experiências face aos contraditórios cotidianos nos quais se inserem.
\end{abstract}

Palavras-chave: juventudes, consumo, educação escolar, educação ambiental.
Abstract

This paper analyzes representations and logics produced by young students from a Rio de Janeiro public school, shared in a focus group on their consumption practices. Inspired by Michel De Certeau, we operate with the notions of "strategy" and "tactics" to understand the interactions of youths with their sociocultural realities, and, from them, the strategies created for the satisfaction of consumer desires or subversion of social devices. promotion to it. Finally, from the narratives of the research subjects, we indicate and debate key elements for the understanding of their experiences against the daily contradictions in which they are inserted.

Keywords: youth, consumption, school education, environmental education.

1 Doutorando em Educação na UFF. Mestre em Educação, licenciado e bacharel em Ciências Biológicas pela UFRJ. Pesquisador associado ao Grupo de Pesquisa Currículo, Docência e Cultura (CDC/UFF/ $\mathrm{CNPq}$ ), onde realiza investigaçôes sobre ensino de Ciências e Biologia na interface entre Currículo e História da Educação. Lattes: http://lattes.cnpq.br/4336934352042664. Orcid: http://orcid.org/00000002-4504-5793. E-mail: rodrigocnb@gmail.com

2 Estudante de graduação na Licenciatura em Ciências Biológicas da UFRJ. Bolsista de Iniciação Científica do Projeto de Pesquisa e Extensão Educação Ambiental para Professores da Educação Básica (EAPEB/ UFRJ). Lattes: http://lattes.cnpq.br/8079240684234438. E-mail: matheusfavrat@gmail.com

3 Professora do Programa de Pós-Graduação em Educação da UFF e da Faculdade de Educação da UFRJ. Doutora em Educação pela UFRJ com estágio pós-doutoral no PROPED/UERJ. Trabalha com a formação de professores de Ciências e Biologia e realiza pesquisas sobre Educação Ambiental, Consumo e Juventudes. Lattes: http://lattes.cnpq.br/5879472477884020. Orcid: http://orcid.org/0000-0003-44193468. E-mail: giraojac@gmail.com 


\section{Introdução}

Devido aos múltiplos fatores que caracterizam o grupo etário, social e biopsicológico da juventude, autores como Dayrell (2003) e Pais (2003) optam pelo termo "juventudes", que ressalta o caráter plural e multifacetado da constituição das identidades juvenis. Sendo a juventude um campo diverso e em disputa, não nos ocuparemos em definir o que é ser jovem, mas consideramos que as juventudes estão condicionadas a aspectos sociais, culturais, históricos e geográficos, bem como às vivências de cada sujeito (DAYRELL, 2003).

A presente investigação busca compreender e problematizar as diversas formas de relação das juventudes com o consumo. De acordo com Costa (2009), essa relação é um importante termômetro para avaliar o modus vivendi das sociedades e suas influências sobre estes "sujeitos sociais": as pessoas jovens (DAYRELL, 2003). Essa argumentação encontra eco em Abramovay e Castro (2015), que criaram cinco categorias para o reconhecimento dos direitos humanos e para políticas e potencialidades das juventudes. Uma delas - identificada como Mundo Espetáculo - considera que as pessoas jovens são atravessadas por uma sociedade de consumo ostentatória, que acaba gerando frustraçóes provenientes de desejos que dificilmente podem ser realizados. Segundo as autoras, os jovens "transitam no seio de uma arquitetura social cuja desigualdade e o acirramento das diferenças constituem algumas de suas faces mais visíveis" (ABRAMOVAY e CASTRO, 2015, p.22).

Nosso interesse sobre a relação juventudes/consumo/escola surgiu a partir de atividades de extensão realizadas com profissionais da Secretaria Municipal de Educação do Rio de Janeiro, nas quais observamos uma forte presença de discursos que enquadram identidades juvenis em consumistas, individualistas, alienadas, hedonistas e outras adjetivaçôes igualmente pejorativas. Marcadas pelo senso comum, estas falas tentam justificar, nos comportamentos dos estudantes, a indisciplina, o uso de drogas, os altos índices de reprovação ou a violência, minimizando, assim, a responsabilidade da comunidade escolar de enfrentar essas e outras questóes que atravessam de diversas formas as juventudes e geram conflitos entre docentes e discentes. De acordo com Dayrell (2007, 1117), “a escola tende a não reconhecer o 'jovem' existente no 'aluno', muito menos compreender a diversidade, seja étnica, de gênero ou de orientação sexual, entre outras expressóes, com a qual a condição juvenil se apresenta”.

Nos últimos anos, no entanto, as identidades juvenis têm sido alvo de pesquisas que problematizam a visão de que a adolescência/juventude é tempo de moratória, rebeldia e irresponsabilidade. Em artigo que trata das relaçóes entre juventudes e novas temporalidades, Fischer e Schwertner (2012) levantam um questionamento sobre características comumente atribuídas às pessoas jovens. 
Juventude: um período de vida obscuro, incerto, repleto de insegurança e instabilidade? Juventude: lugar da irresponsabilidade, da ansiedade, da alienação, das experiências de risco e violência? Juventude, afinal: sempre um problema? $\mathrm{O}$ senso comum parece insistir numa discursividade que associa o jovem a alguém muitas vezes perdido em um corredor escuro, para o qual só resta a "luz" do mundo adulto - lugar do equilíbrio e da autonomia, muito distante daqueles tempos e lugares incertos e tortuosos por ele vividos. (FISCHER e SCHWERTNER, 2012, p. 396).

A partir do desconforto gerado pelos discursos docentes, buscamos conhecer e problematizar hábitos e percepçóes sobre consumo de jovens por meio de oficinas desenvolvidas com estudantes de três escolas públicas cariocas. Os debates culminaram em duas questôes: qual é o seu sonho de consumo e qual é o seu sonho que não envolve consumo? Os resultados desta primeira etapa da pesquisa - apresentados em Bastos et al. (2015) - nos mobilizaram a ampliar seu escopo e investir na relação juventudes/consumo e educação escolar, identificando mediaçóes e intervenções realizadas pelas escolas a respeito da cultura do consumo, seja em ações curriculares de disciplinas específicas, seja em projetos voltados a toda a comunidade escolar. Trilhando esse caminho, passamos a investigar a problemática do consumo e das juventudes a partir de entrevistas com docentes e discentes de uma escola pública federal e uma escola pública estadual, ambas localizadas na zona sul do Rio de Janeiro. Os resultados relativos à escola federal estão descritos em Souza e Lima (2018).

Neste artigo, apresentamos dados e discussões referentes às entrevistas com estudantes de uma escola pública estadual que oferece o Ensino Médio nas modalidades Regular, Educação de Jovens e Adultos e Formação de Professores, com a qual temos parceria para atividades de pesquisa e extensão. Nesta escola realizamos, em 2018, uma entrevista de tipo grupo focal com estudantes da $3^{a}$ série do curso de formação de professores em nível médio (normal), sobre como veem a relação das pessoas jovens com o consumo e quais mediações, na percepção delas, são realizadas pela escola em questão. Discutimos as impressóes dos sujeitos da pesquisa sobre o atual modelo de sociedade baseado no consumo de bens e de identidades, o posicionamento da escola diante dessa questão e o papel da mídia na promoção de desejos de consumo e na construção das culturas juvenis.

Essa investigação se insere no âmbito de um projeto de pesquisa e extensão sobre educação ambiental em contextos escolares. Focalizamos práticas, currículo e formação docente (inicial e continuada). Mais recentemente, nossos 
interesses se aproximaram de estudos sobre as mediaçóes realizadas pela escola em relação à problemática do consumo e as formas como os estudantes se relacionam com a mesma. Sendo o consumo um tema central da educaçáo ambiental que influencia na formação de identidades juvenis, acreditamos que nossa pesquisa representa um diálogo potente entre os campos da educaçáo ambiental e da juventude.

$\mathrm{Na}$ primeira parte do texto, compartilhamos reflexóes sobre as relaçóes imbricadas entre consumo e juventudes, a fim de contextualizarmos teoricamente as ideias que balizam os debates suscitados. Em seguida, apresentamos os procedimentos metodológicos selecionados para a produção de dados nesta pesquisa e, na seção posterior, empreendemos discussóes a partir de referenciais dos campos sociológico e filosófico que dialogam com os estudos sobre culturas juvenis. À guisa de conclusão, elencamos algumas considerações que reverberam os caminhos percorridos e suscitam questóes para futuras iniciativas.

\section{Consumo e juventudes: relações complexas e contraditórias}

O avanço do neoliberalismo - ou, mais recentemente, do ultraliberalismo produz uma sociedade constantemente mutável, que vivencia o desmoronamento de direitos sociais antes consolidados, como moradia, emprego, educação e previdência social. Nessa nova ordem, verdadeiras Leônias ${ }^{4}$ se levantam todos os dias, imersas na lógica do consumo e da efemeridade dos bens materiais e das relações pessoais.

Segundo Costa (2009a, p. 35), "o consumo é o centro organizador da ordem social, política, econômica e cultural do presente, e todos nós somos 'educados' para e por ele". Para esta sociedade que explora e se reinventa, tudo se transforma em mercadoria: bens naturais, pessoas, estilos de vida e serviços. Bauman (2008), por sua vez, nos ajuda a entender como a sociedade de produtores transformou-se em sociedade de consumidores: nesse segundo modelo, a transformação de pessoas em mercadorias se dá a partir de sua necessidade de serem notadas e aceitas no espaço social, em um mundo onde tudo se torna efêmero. A conhecida metáfora dos líquidos de Bauman (vida líquida, modernidade líquida etc.) também se aplica às mudanças que têm curso nas sociedades pós-industriais que se consolidaram a partir da década de 1980.

4 Leônia é uma cidade fictícia criada por Ítalo Calvino no livro As cidades invisíveis. Leônia se refaz a si própria todos os dias, acordando com produtos novíssimos enquanto os restos da Leônia de ontem são prontamente descartados. A verdadeira paixão dos moradores de Leônia consiste no ato de expurgar as impurezas do que é velho e não no prazer da novidade. O lixo repelido por Leônia acaba por se acumular nos arredores da cidade, em montanhas do lixo de ontem e anteontem que um dia irão desmoronar sobre a metrópole. 
Sinergicamente, Costa (2009a) ressalta que nossa educação é voltada para uma vida baseada no consumo. Essa visáo decorre da influência da sociedade de consumidores (BAUMAN, 2008) na cultura e demais aspectos da vida contemporânea, em que o consumo exerce um papel de identificador social (COSTA, 2009). Nesse sentido, Fontenele (2017) destaca a importância da cultura do consumo - uma outra face da sociedade de consumidores - nas relaçóes humanas. Dentre os elementos que nos indicam como se deu a consolidação da cultura do consumo nas sociedades ocidentais, destacamos: trabalho infantil, exploração sexual, devastação da natureza e questóes ligadas aos jovens residentes em áreas rurais e/ou de extrema pobreza.

$\mathrm{Na}$ visão de Fontenele (2017), a versão contemporânea do consumo surge na passagem da sociedade de produtores à sociedade de consumidores, ou seja, do consumo ao consumismo, dos bens duráveis à obsolescência programada (BAUMAN, 2008). Neste contexto, a sociedade é convidada "ao deleite consumista, ou melhor, ao desempenho de um papel social que privilegia a satisfação instantânea em detrimento do adiamento/postergaçáo dos desejos" (OLIVEIRA e TOMAZETTI, 2012, p.190). Em diálogo com Margulis e Urresti (1996), Abramovay e Castro (2015) ressaltam que ser jovem também está associado a uma estética que leva a sociedade a comercializar seus atributos, inclusive imagens, como mercadorias que podem ser compradas e vendidas.

Ainda segundo Fontenele (2017), a imagem é o aspecto central da cultura do consumo, sobretudo no que a autora considera a segunda fase desta cultura, que teve início após a segunda guerra mundial. A partir deste período, cultura e economia modelam os sujeitos por meio de marcas e imagens. $\mathrm{Na}$ sociedade de consumidores, os produtos são vendidos não pelo seu valor intrínseco, mas por sua associação àquilo que as pessoas desejam ser: jovens, atléticas, ricas, atraentes, admiradas. Assim, o ser humano passa a ser um produto anunciado e consumido, formando uma "subjetividade consumidora de mercadorias [...] para além da ideia da mera utilidade do objeto" (FONTENELE, 2017, p.58).

O consumo é também "o lugar em que se completa o processo iniciado com a geração de produtos, onde se realiza a expansão do capital e se reproduz a força de trabalho" (CANCLINI, 1995, p.53). Complementando a visáo deste autor, podemos entender que, na sociedade de consumidores, as pessoas vendem sua força de trabalho e a si mesmas para o sistema capitalista, que sustenta seu poderio à custa da exploração dos seres humanos e da natureza. Este cenário gera instabilidade em todos os setores da sociedade e produz muitas incertezas quanto ao futuro. Aqueles que sentem os reflexos das mudanças sociais de maneira mais incisiva são as pessoas jovens, que, introduzidos na lógica frenética do consumo desde a infância, no limiar da vida adulta se deparam com inúmeras 
responsabilidades e fardos, mas não conseguem vislumbrar perspectivas de empregabilidade e melhoria das condiçóes materiais de sobrevivência.

Com o aumento da insegurança no mercado de trabalho e as altas taxas de desemprego no país e no mundo, restam-lhes os cargos mais precarizados ou o mercado informal, volátil e instável. De acordo com o relatório "Perspectivas Sociais e de Emprego no Mundo: Tendências 2018”, publicado pela Organização Internacional do Trabalho (OIT), o emprego vulnerável aumenta e o ritmo de reduçáo da pobreza entre trabalhadores sofre desaceleração. Para as pessoas negras e jovens de periferia, essa situação é ainda mais dramática, pois seus corpos e territórios são socialmente lidos de modo estigmatizado (MADEIRA e GOMES, 2018).

Por outro lado, de acordo com Dayrell (2003), condiçóes sociais anteriores ao nascimento da pessoa e que carregam sentidos forjados socialmente como a raça, o gênero, a origem e a escolaridade parental, são dimensóes que, independentemente da ação de cada um, têm potencial de interferir na produção de cada jovem como sujeito social. Assim, o avanço de políticas de controle de corpos e territórios que vimos presenciando sobrecarrega o fardo das juventudes das classes populares que muitas vezes trabalham, estudam e ainda vivenciam duplas ou triplas jornadas de trabalho. Além disso, muitas jovens assumem sozinhas a responsabilidade do sustento e cuidados com a família.

Nesse contexto, cabe refletir sobre o lugar ocupado pela instituição escolar, que se constitui como uma arena onde ideias, gostos, hábitos e culturas se encontram, mas nem sempre estabelecem diálogos. Assim como a família, os espaços de socialização religiosa e de trabalho, a escola pode estar a serviço da manutenção do status quo ou de seu questionamento, tendo como direcionamento a transformação da hegemonia cultural e das estruturas de poder da sociedade (LAHIRE, 1997). Apostamos na segunda opção, mas sabemos que essa condição não está dada: é preciso reconstruir e democratizar a escola (DAYRELL, 2007). Os estudos sobre juventudes, no nosso entender, têm contribuiçôes importantes a oferecer neste movimento de avaliar e repensar essa instituição, a partir do conhecimento sobre as demandas juvenis, suas identidades, anseios e dificuldades.

\section{O cenário e os procedimentos da pesquisa}

A escola parceira da pesquisa é uma instituição pública peculiar, pois oferece o Ensino Médio sob diferentes modalidades: formação de professores, regular e educação de jovens e adultos (EJA). Assim, além das disciplinas que tradicionalmente compóem os currículos para o Ensino Médio, são também oferecidas aquelas de formação pedagógica, dentre as quais muitas se relacionam diretamente às discussóes e abordagens da educação ambiental (EA). Nesse bojo, destacamos a disciplina 
"Vida e Natureza", que tem como característica principal ser um "laboratório pedagógico" no qual os estudantes pensam e elaboram materiais didáticos e atividades relacionadas ao ensino de Ciências Naturais para serem utilizados em seus estágios de prática de ensino em escolas municipais do Rio de Janeiro.

Situado no bairro do Jardim Botânico, o colégio atende a quase mil estudantes oriundos de diferentes bairros e realidades socioculturais do município do Rio de Janeiro. As turmas são marcadamente heterogêneas, com predomínio de estudantes que subsistem em cotidianos marcados pelas desigualdades sociais e injustiças ambientais das favelas e periferias cariocas.

Em agosto de 2018, foi realizado uma entrevista de tipo grupo focal (GATTI, 2005; GOMES, 2006) com 12 estudantes da $3^{\text {a }}$ série do Ensino Médio na modalidade do curso de formaçáo de professores, pertencentes a um grupo de apoio à escola no tempo integral. Todos tinham 17 ou 18 anos de idade. $\mathrm{O}$ grupo era constituído por uma pluralidade de sujeitos, não apenas nos critérios relativos a gênero ou raça, mas também quanto aos territórios de origem.

A entrevista foi agendada diretamente com a direção da escola, que "disponibilizou" os estudantes e um espaço para a realizaçáo da mesma. Estiveram presentes a coordenadora do projeto, um bolsista e um ex-bolsista de extensão, que participou da primeira fase da pesquisa. Seguimos um roteiro semiestruturado de perguntas que permearam as visóes de consumo dos e das jovens, suas práticas de consumo, as mediaçóes realizadas pela escola e, por fim, seus sonhos de consumo e aqueles que não envolvem a aquisição de bens materiais. Os e as estudantes se mostraram bastante à vontade para expressar suas opiniôes, mesmo quando sabiam que poderiam não ser bem aceitas pela maioria (como, por exemplo, ao assumirem que são consumistas). Atribuímos este fato à conversa inicial com o grupo, na qual explicamos que nosso objetivo não era fazer julgamento de valores, mas entender as relaçóes que os sujeitos estabelecem com o consumo e as intervençóes da escola acerca do tema. Possivelmente, a presença de dois jovens na equipe (o bolsista atual e o ex-bolsista de iniciação científica) fortaleceu a confiança e o interesse dos estudantes na pesquisa. Foi garantido, também, seu total anonimato.

Para Ferreira e Raimundo (2017), dentre as "artes e manhas do entrevistador" está a capacidade de contornar os dispositivos de excecionalidade (FERREIRA e RAIMUNDO, 2017) próprios de uma entrevista - tais como gravadores e câmeras - e "armar-se dos artifícios de naturalidade que levam a que os interlocutores sintam essa interação como um momento de conversa interessante, mais do que interessada ou até interesseira" (p. 57). O grupo focal, para estes autores, tem como marca distintiva a "utilização explícita da interação grupal" entre vários participantes,

Todos os grifos são dos autores. 
para a produção de dados discursivos em contexto de pesquisa" (FERREIRA e RAIMUNDO, 2017, p. 65). É, pois, metodologia participativa na qual as interações entre os sujeitos e entre os sujeitos e pesquisadores/as são valorizadas e estimuladas. Inspiramo-nos também em Brites (2017), que, em pesquisa realizada com 32 jovens portugueses, utilizou processos participativos, "para facilitar procedimentos de reflexão e de participação dos sujeitos na investigação" (p. 91), que atuaram como quasi-investigadores. A autora considera que

Numa sociedade "adultocêntrica", há temas, espaços e lógicas relacionados com a juventude que estáo praticamente vedados aos jovens, por estes serem, não raras vezes, vistos como adultos em construção. As entrevistas e os grupos focais constituem-se como excelentes pontos de partida para um trabalho participativo, no qual a robustez das propostas já consagradas pode ser completada com uma participação efetiva dos participantes da pesquisa. (BRITES, 2017, p. 105).

Outras entrevistas estáo sendo realizadas com docentes da escola, a partir de nosso interesse sobre as mediações realizadas por essa instituição no que tange às questôes relativas ao consumo juvenil. Neste trabalho, optamos por apresentar as visóes dos estudantes a respeito do consumo, que, em outro momento, serão discutidas em conjunto com a segunda parte da empiria da pesquisa: as percepçóes dos docentes sobre a relação das pessoas jovens com o consumo e as práticas pedagógicas desenvolvidas para problematizar essa questão.

\section{Entre estratégias e táticas: quando as juventudes são atravessadas pelo consumo e interpelam o consumismo}

Nesta seção, trazemos algumas pistas para pensarmos sobre diferentes estratégias e táticas ${ }^{6}$ mobilizadas por sujeitos desta pesquisa para lidar com o consumo/ consumismo a partir das narrativas produzidas durante o grupo focal. Tais noçóes,

6 Para De Certeau (1998, p.99), a estratégia é o "cálculo (ou a manipulação) das relações de forças que se torna possível a partir do momento em que um sujeito de querer e poder (uma empresa, um exército, uma cidade, uma instituição científica) pode ser isolado". Já a tática é "a ação calculada que é determinada pela ausência de um próprio. Então nenhuma delimitaçáo de fora lhe fornece a condição de autonomia. A tática não tem por lugar senão o do outro. E por isso deve jogar com o terreno que lhe é imposto." (DE CERTEAU, 1998, p. 100). 
elaboradas por Michel De Certeau (1998), foram acionadas com o fim de indicarmos as diferentes, complexas e muitas vezes contraditórias apropriaçóes exercidas pelas juventudes diante dos dispositivos culturais promotores do consumo.

Durante o grupo focal, os estudantes levantaram, dentre outras questóes, uma discussão sobre a economia das trocas simbólicas (BOURDIEU, 2004) em nossa sociedade. Um caso que nos chamou a atenção, contado de maneira quase compartilhada por todos os estudantes da $3^{a}$ série presentes, foi a respeito da "camisa do terceirão ${ }^{7}$." A turma escolheu um desenho de arco-íris para estampar a camisa personalizada, mas alguns estudantes foram contra a presença deste símbolo porque, segundo eles, remetia à cultura LGBTQIA+. "As pessoas são conhecidas pelas marcas que elas deixam" e "As marcas dão identidade ao grupo" foram posicionamentos que surgiram no grupo focal ao comentarem o ocorrido.

Durante esta discussão, alguns estudantes lembraram do documentário " $\mathrm{O}$ Preço do Progresso - A Epidemia do Tabaco" trabalhado em sala de aula por um professor. $\mathrm{O}$ trecho comentado foi sobre o caso da indústria de cigarro que, ao perceber que náo lucrava com o nicho de consumo feminino, impulsionou um discurso massivo de emancipaçáo feminina em torno do consumo do cigarro, hegemonizando como ato revolucionário a prática do tabagismo entre mulheres e, consequentemente, o crescimento no consumo do produto. Dialogando com este caso, o debate girou em torno da comercialização dos movimentos sociais e a apropriação de lutas anti-opressão, como a luta das mulheres, do movimento negro e do movimento LGBTQIA+, por grandes empresas que vêem nesses grupos sociais mais nichos de mercado a serem explorados.

Indagados sobre seus sonhos, alguns participantes fizeram alusão a um conceito ampliado de liberdade fundamentado na independência financeira, essencial para a realizaçáo de seus desejos de consumo e de realização pessoal. Uma das estudantes revelou que preza muito pela liberdade e almeja alcançála. Tal liberdade, contudo, não residiria apenas em independência jurídica e financeira diante de seu arcabouço familiar, mas em autonomia para vivenciar suas próprias escolhas, que seriam cerceadas por seus pais e pela sociedade, de modo acentuado pela sua condição feminina. Outra, por sua vez, abordou sua relação com a autoestima, revelando que, nos dias em que se sente feia, lança mão do dispositivo de compra como refúgio da realidade que produz padróes corporais e idealiza o "belo" e o "feio".

7 Os estudantes da turma de 3a série do Ensino Médio de Formação de Professores de 2018 tiveram a iniciativa de produzir uma estampa que representasse a turma, com o nome dos estudantes, como forma de se recordarem dos colegas após a conclusão do Ensino Médio. Este é um ato que está se tornando comum em algumas escolas do Rio, semelhante ao costume mais antigo de "assinar" coletivamente as blusas uns dos outros após o término do ano letivo. 
Também despontou o desejo de sair do Brasil em busca de segurança e acolhimento, tendo em vista a potencialização da cultura da violência e da intolerância às diferenças que se concretiza em altos índices de feminicídio ${ }^{8} \mathrm{e}$

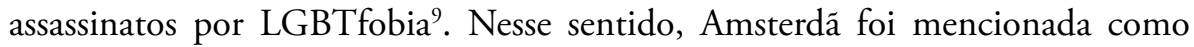
uma cidade mais acolhedora para a população LGBTQIA+. A propósito, a jovem que apontou que morar na capital holandesa permitiria a conquista de sua liberdade, em seguida revelou que seu maior sonho não é a viagem a esta cidade, mas sim a aceitação de sua família perante sua orientação sexual, que foge ao padrão heteronormativo vigente.

Além disso, foi apresentado como anseio coletivo dessas jovens a possibilidade de trilharem caminhos que permitam o desvio de angústias e sofrimentos atrelados às leituras socioculturais que são feitas de seus corpos constituídos e atravessados por questôes de classe, gênero, raça e sexualidade. Para os sujeitos e sujeitas dos sonhos narrados, suas liberdades estão condicionadas ao território de residência, ao poder aquisitivo ou mesmo à aprovação de sua conduta perante as famílias.

Assim, partimos do princípio que processos estratégicos (DE CERTEAU, 1998) de reproduçáo econômica associados ao fomento e à regulaçáo de práticas de consumo juvenil podem ser dissimulados por discursos e outros artefatos culturais, simultaneamente ao acirramento de disparidades entre os jovens. $\mathrm{O}$ resultado desses mecanismos pode culminar em potentes violências simbólicas associadas a demarcaçóes de distinçóes que classificam, hierarquizam, enobrecem ou estigmatizam os sujeitos e seus respectivos grupos sociais (BOURDIEU, 1989; 2008) ao mesmo tempo que incentivam o consumo.

Nesse bojo, falas a respeito do significado de ser consumista, como "aquela linha entre o querer e o precisar. Tipo, eu não preciso, mas eu quero uma coisa. Suprir uma necessidade que não é prioridade, na verdade", "sobreviver é o que dá limite ao consumo. Tipo sobreviver, comida, teto", ou "porque eu posso precisar, uma pessoa pode precisar e outra não; as minhas necessidades não são as mesmas que a suas" sugerem que a diferença entre o querer e o precisar, entre a necessidade (im)posta pela realidade e a compulsão insuflada pela indústria cultural, é bastante tênue e subjetiva, tendo sentidos mutáveis de acordo com as experiências de vida e contextos sociais em que cada sujeito ou grupo social está inserido. Portanto, as demandas por sobrevivência impóem limites ao consumo: os custos com moradia e alimentação foram pontuados como importantes fatores que limitam o ímpeto consumista.

8 Mapa da Violência 2015: Homicídio de Mulheres no Brasil. Disponível em: <http://flacso.org. br/?p=13485>. Acesso em 11 de ago. de 2019.

9 Relatório Populaçáo LGBT morta no Brasil Grupo Gay da Bahia 2018. Disponível em: <https:// homofobiamata.files.wordpress.com/2019/01/relatorio-2018-1.pdf>. Acesso em 11/08/2019. 
Uma outra dimensão associada à sociedade de consumidores (BAUMAN, 2008) foi apontada pelos estudantes como relacionada às novas estratégias de exploração e de dominação pautadas no disciplinamento tecnológico, como se percebe na resposta de uma estudante sobre a comunicação em tempos anteriores à internet ou a dispositivos eletrônicos: "eu acho que com o tempo gerou uma certa dependência da gente precisar, sabe, do meio tecnológico, conforme a sociedade foi se modificando a gente gerou essa necessidade." Quando indagados a respeito do quão essencial seria o uso de telefones celulares em seus cotidianos, não foram vislumbradas alternativas para o mesmo. Inclusive, imaginar os sujeitos do passado se comunicando na ausência deste aparelho, da internet e de outros dispositivos e tecnologias de informação e comunicação (TICs) atuais, foi um exercício difícil de ser realizado.

A influência da propaganda presente nas mídias digitais também foi apontada como decisiva para o estímulo ao consumo. A sedução operada pelas TICs, bem como as representaçóes ${ }^{10}$ naturalizadas e legitimadas pelos discursos que as atravessam, transformaram e organizaram as noçóes de tempo e de espaço, fazendo emergir novas identidades culturais e sociais (AMARAL, 1997). A esse respeito, selecionamos uma fala bastante elucidativa de uma das estudantes: "eu acho também que é questão de influência digital. Que a toda hora tem negócio de anúncio que é exatamente pra instigar a gente a comprar essas coisas, de repente, acha bonito, acha legal. Tipo celular, a gente compra um esse ano e ano que vem aparece um celular maneiro e a gente quer. E eu vejo isso daí toda hora".

Se compreendermos que também a sedução, e não apenas a força, pode ser usada pelos estrategistas para impor práticas, produzir modelos e criar representaçóes, às vezes até de modo consentido pelos sujeitos que sofrem a ação (DE CERTEAU, 1998), perceberemos nas falas dos e das estudantes indícios de como são levados a consumir, mesmo que situados nas classes subalternizadas, ou seja, sob condiçóes mais restritas de acesso a recursos materiais e simbólicos.

Ao serem indagados a respeito de sonhos que não envolvessem o consumo de bens materiais, muitos estudantes compartilharam o desejo de construir uma família e de modo recorrente demonstraram afeto por seu bairro/favela. Uma jovem contou que participa da Roda Cultural da Rocinha e que os produtores culturais da roda, segundo ela, "sempre estáo em prol da comunidade, recolhendo alimentos e agasalhos para distribuir para quem precisa" e "batalhando para que a roda aconteça, trazendo atraçóes que a gente nunca imaginava que veria na Rocinha.” As Rodas Culturais são manifestaçóes gratuitas e em locais abertos,

10 Neste texto, o conceito de representaçóes adotado é aquele apresentado e debatido por Amaral (1997). Para detalhes dessa discussão, ver o referido artigo. 
auto-organizadas pelos artistas locais. Os eventos garantem um espaço para intervençóes de músicos, DJs, MCs, poetas, grafiteiros e diversos outros artistas. As rodas extrapolam praças e ruas e se espalham pelas periferias, ruas e favelas do Rio de Janeiro, criando um intercâmbio cultural entre as juventudes fluminenses.

Essa jovem, que sonha em ser mestre de cerimônia de Rodas Culturais, durante a entrevista manifestou vontade de construir algum projeto que "tenha impacto na vida das pessoas da minha comunidade", revelando que é uma dos muitos sujeitos que constroem relaçóes na nova cena cultural das ruas, com os eventos de cultura popular que redesenham o espaço público. No espaço compartilhado entre jovens artistas há a valorização do consumo de um estilo construído em torno de um gênero musical, forjando sujeitos sociais através das vivências de seu contexto social (DAYRELL, 2003).

Algo a ser destacado é a impressáo de que práticas consumistas poderiam ser de certo modo herdadas das famílias, de acordo com o relato de alguns estudantes, como em:

eu acho que eu sou consumista, porque é uma coisa que já está na minha família há muito tempo. Minha mãe nem sempre teve condiçóes de comprar o que ela queria, mas a partir do momento que ela conseguiu, ela passou a comprar em excesso. Mesma coisa com a minha irmã. Eu tenho uma certa influência delas, eu acabo também comprando as coisas em excesso porque eu vejo todo mundo fazendo isso.

Nesse caso, mesmo que percebidas como não inatas ou hereditárias, tais práticas seriam aprendidas no seio familiar. Aproximando-nos novamente de Bourdieu (2011), podemos reunir indícios nesses depoimentos sobre certo habitus "consumista" que seria incorporado e inconscientemente adquirido pelos estudantes a partir das experiências familiares. Afinal, as famílias são os espaços sociais matriciais onde se ensinam modos de pensar, agir e sentir aos sujeitos. A ânsia por consumir, produzida socialmente, encontra eco desde o momento do nascimento e é internalizada por todos.

No entanto, se estratégias (DE CERTEAU, 1998) para estimular o consumo afetam as pessoas jovens mesmo antes delas nascerem, seus posicionamentos no jogo social não são meramente passivos, já que não assistem atônitos a suas vidas passarem. Por isso, táticas (DE CERTEAU, 1998) também são elaboradas e erigidas pelas juventudes para se desviar das normas, resistir às imposiçóes ou manipular as situaçóes e produzir efeitos inesperados a partir delas. Reforçamos que, diante de nosso escopo de pesquisa e em sintonia com o autor que nos serve de referência para esse debate, compreendemos como comportamento juvenil tático (DE CERTEAU, 1998) não somente aquele que evita desenvolver hábitos tidos usualmente como 
consumistas, mas sobretudo aquele que se serve das circunstâncias desfavoráveis para burlar, ressignificar ou operar de modo imprevisível com dispositivos de controle e regulação social associados à lógica do consumo.

Nesse contexto, o que nos interessa é conhecer e compreender a pluralidade e a criatividade com as quais jovens provenientes de classes sociais menos favorecidas economicamente criam intermediaçóes e assimilaçóes dentro do sistema. Assim como De Certeau (1998), entendemos que cada sujeito social realiza operaçóes próprias e peculiares com o que lhe é oferecido. Por isso, conhecer e interpretar os usos inventivos, clandestinos, invisíveis e silenciosos das juventudes diante do cerco cada vez mais totalitário dos estrategistas, se coloca como um programa produtivo para investigações futuras.

No grupo focal, estudantes se posicionaram de diferentes formas na relação com o consumo. Enquanto alguns buscaram apresentar uma visão crítica sobre a temática, outros se assumiram consumistas e fizeram questão de informar os mecanismos criados para garantir que seus desejos por consumir pudessem ser satisfeitos - como em "não é nem pelo objeto, é pela vontade de ter, quando compra, acabou" - ainda que as condiçóes nem sempre fossem favoráveis. O trabalho remunerado antes da maioridade legal, a articulaçáo com amigos e familiares e a reprodução de discursos pró-consumo fazem parte do repertório de táticas (DE CERTEAU, 1998) desse grupo de jovens que almeja reafirmar e atualizar suas experiências no tabuleiro social (DE CERTEAU, 1998, p. 92). Táticas que, contraditórias tais quais as realidades sociais em que estáo imersas, assumem traços das estratégias que outros denunciaram.

Sendo consumidores-esfinge (DE CERTEAU, 1998, p. 94), os jovens tentam se apropriar de elementos e produtos da cultura para subverter os processos de controle e regulação de suas práticas. Mesmo que as vitórias na instância cotidiana sejam efêmeras, a produção astuta de novos sentidos para o consumo que realizam nos auxilia a entender como esses sujeitos manipulam e invertem deliberadamente, na surdina, as restrições que os subjugam. Metaforizando a ordem dominante, vulgarizam de modo quase invisível e degradam silenciosamente de forma tática (DE CERTEAU, 1998) o sistema que os assimila, permanecendo diferentes em seu interior.

\section{Pode a liberdade ser comprada? - considerações provisórias}

As reflexões dos e das estudantes corroboram a perspectiva de Costa (2009a), de que as necessidades na sociedade de consumidores são condicionadas pela lógica efêmera dos desejos, fortemente influenciadas pelo marketing e propagandas publicitárias (FONTENELE, 2017). A temática do consumo é bastante afeita 
a julgamentos morais em relação à forma como as pessoas vivenciam essa prática: a própria sociedade de consumidores (BAUMAN 2008), se encarregou de criar categorias que circunscrevem os sujeitos em "consumidores conscientes", "consumistas" e outras. Abordar a questão do consumo com as pessoas jovens é, entâo, um duplo desafio, pois, de acordo com Ferreira e Raimundo (2017, p.58):

(...) as experiências juvenis com dispositivos dialógicos de inquiriçâo por parte de adultos significativos, como pais ou professores, por exemplo, podem ser associadas a dispositivos adultocêntricos de avaliação ou controle social através da pergunta. Podem também ser experiências (pres) sentidas pelos jovens como envoltas em paternalismo, pois muitas vezes as instituiçóes que mais de perto os enquadram pretendem ouvir as suas vozes, mas de uma forma mais consultiva do que deliberativa.

Nesse sentido, consideramos que a metodologia utilizada nesta pesquisa - o grupo focal - pelos motivos já mencionados, se mostrou bastante adequada para a produção de dados, baseada, sobretudo, nos diálogos entre os e as estudantes participantes da pesquisa. É importante destacar que esses jovens, por serem oriundos do curso de formação de professores e estarem cursando sua etapa final - ou seja, se aproximando da entrada no mercado de trabalho - têm um acúmulo de experiências, reflexóes e anseios próprios desta condição, o que, certamente, enriqueceu os diálogos travados ao longo de uma hora e quarenta e quatro minutos de entrevista. Acreditamos ainda que a imersão dos estudantes nos contextos de estágio acrescentou vivências importantes para a nossa questão de pesquisa, já que lidam com a infância e percebem, nesta faixa etária, os primeiros indícios do surgimento de "consumidores mirins", os quais contrastam com experiências de suas próprias infâncias.

Retornando à indagação que abre essa seção, argumentamos que, ao fazer um exercício de imaginar sociedades livres de opressóes, é possível alcançar uma noção aproximada de liberdade. Para Nina Simone, artista e ativista da luta pelos direitos civis da população negra nos Estados Unidos, liberdade é não ter medo. Dialogamos com seu pensamento para compreender a limitaçáo do exercício da liberdade perante as complexas relaçôes forjadas na sociedade de consumidores, especialmente para aqueles e aquelas que não se enquadram nos padrões hegemônicos de estética, gênero, orientação sexual, classe social, raça e etnia.

Concordamos com Sarlo (2013, p.55), que, em seu livro "Cenas da vida pós moderna", afirma que "o mercado promete uma forma do ideal de liberdade e, na sua contraface, uma garantia de exclusão”. A autora, no entanto, não apresenta saída para as juventudes que se deslocam em meio às promessas de liberdade 
oferecidas pelo mercado e a escola que, segundo ela, teve seu prestígio reduzido "tanto pela queda das autoridades tradicionais quanto pela conversão dos meios de massa no espaço de uma abundância simbólica que a escola não oferece". (SARLO, 2013, p. 53).

A respeito dos conflitos entre jovens e a escola, Dayrell (2007) traz importante contribuição ao apontar que "o problema não se reduz nem apenas aos jovens, nem apenas à escola, como as análises lineares tendem a conceber" (DAYRELL, 2007, p. 1106). O autor aposta que "as tensóes e os desafios existentes na relaçáo atual da juventude com a escola são expressóes de mutaçóes profundas que vêm ocorrendo na sociedade ocidental, que afetam diretamente as instituiçóes e os processos de socialização das novas geraçóes" (p. 1106) e propóe que o eixo de reflexão se desloque das instituiçóes educativas para os sujeitos jovens. Nesse sentido, é "a escola que tem de ser repensada para responder aos desafios que a juventude nos coloca” (p. 1107).

Se pensarmos que, há bem pouco tempo, centenas de jovens ocuparam escolas e universidades do país reivindicando educação de qualidade e condiçóes de trabalho e de remuneração dignas para seus professores e que deste movimento surgiram, naquelas instituiçóes, coletivos de resistência contra o machismo, o sexismo, o racismo e a LGBTfobia, podemos concluir que a educação ainda ocupa um espaço importante nos "sonhos" juvenis. Como informam Schwertner e Fischer (2012, p. 397), "recentes estudos se apropriam de diferentes pontos de vista teóricos e convertem o olhar, de modo a pensar o jovem como protagonista, como criador e até mesmo como agente de transformação das formas de vida de que fazem parte, em diferentes ambientes sociais, econômicos e culturais".

Assim, se "a escola faz as juventudes" (DAYRELL, 2007), argumentamos que as juventudes também fazem a escola a partir de suas vivências e culturas. É fundamental, então, que a escola abra um canal de escuta às táticas mobilizadas pelas juventudes para lidar com os desafios impostos pela sociedade de consumo/ consumidores, afastando-se de julgamentos moralistas e encontrando formas dialogadas de problematização e questionamento sobre as causas e consequências deste modelo de sociedade.

Acrescentamos que os e as estudantes da nossa pesquisa mencionaram várias atividades - como documentários, leitura de textos e debates - realizadas em sala de aula por professores em relação ao consumo. Segundo estes jovens, proporcionar espaços de discussão sobre consumo no contexto escolar é importante para evitar conflitos gerados por desigualdade de renda cultivando a noção de solidariedade entre os colegas, desenvolver a percepção a respeito dos problemas ambientais e a necessidade urgente de reverter esta situaçáo e tornar a escola cada vez mais um espaço aberto às diferenças. 
Tal fato reforça nossa aposta na centralidade da escola para - nas palavras dos estudantes - a formação de uma "cidadania consciente" - ou seja, para a problematização dos padrōes societários fundamentados no consumo, no individualismo e na competitividade. Mesmo em tempos de recrudescimento do conservadorismo representado por movimentos como o "Escola sem partido" - e por restriçóes impostas pelas próprias redes de ensino, há educadores e educadoras que criam suas táticas de resistência a partir do conhecimento e do debate, fundamentais para todos e todas que se proponham a exercer a docência com criatividade, coragem e respeito. Finalizamos por ora encorajando pesquisadoras e pesquisadores a investirem em trabalhos que focalizem as estratégias e táticas das juventudes diante dos complexos desafios postos pela sociedade de consumidores (BAUMAN, 2008).

\section{Referências}

ABRAMOVAY, M.; CASTRO, M. G.. Ser jovem no brasil hoje: políticas e perfis da juventude brasileira. Cadernos Adenauer, n.1, v.16, 2015. Disponível em: <http://www.kas.de/wf/doc/16488-1442-5-30.pdf>. Acesso em 10 abr. 2018.

AMARAL, M. B. Tele natureza e a construção do natural: um olhar sobre imagens de natureza na publicidade. In: OLIVEIRA, D. L. (Org.). Ciências nas salas de aula. Porto Alegre: Editora Mediação, 1997, p. 83-960.

BAUMAN, Z. Vida para consumo: a transformação das pessoas em mercadoria. Rio de Janeiro: Jorge Zahar, 2008.

BASTOS, C. B.; SOARES, A. G.; FIGUEIRA, M. R.; ASSUMPCAO, T. L.; LIMA, M. J. G. S. Sonhos de consumo?: uma pesquisa com jovens de duas escolas públicas do município do Rio de Janeiro. In: VIII Encontro Pesquisa em Educaçáo Ambiental, 2015, Rio de Janeiro - RJ. Anais VIII EPEA, 2015.

BOURDIEU, P. O poder simbólico. Rio de Janeiro: Bertrand, 1989.

BOURDIEU, P. A distinçáo: crítica social do julgamento. São Paulo: EDUSP; Porto Alegre: Zouk, 2008.

BOURDIEU, P. A economia das trocas simbólicas. 5a ed. São Paulo: Perspectiva, 2004.

BOURDIEU, P. Razóes Práticas: sobre a teoria da ação. Campinas: Papirus, 2011 .

BRITES, M. J. Quando a investigação é feita com participantes ativos: ampliar o uso de técnicas de entrevista e de grupo focal. In: FERREIRA, V. S. (Org). 
Pesquisar Jovens: caminhos e desafios metodológicos. Lisboa, Imprensa de Ciências Sociais, 2017, p. 91-109.

CALVINO, I. As cidades Invisíveis. 2. ed. São Paulo: Companhia das Letras, 1990.

CANCLINI, N. G. Consumidores e Cidadáos: conflitos multiculturais da globalização. Rio de Janeiro, Editora UFRJ, 2001.

COSTA, M. V. Há estranhos nas escolas. In: COSTA, M. V. (Org.). A Educaçáo na Cultura da Mídia e do Consumo. Rio de Janeiro: Lamparina, 2009.

COSTA, M. V. Educar-se na Sociedade de Consumidores. In: COSTA, M. V. (Org.). A Educaçáo na Cultura da Mídia e do Consumo. Rio de Janeiro: Lamparina, 2009a.

DAYRELL, J. T. O jovem como sujeito social. Revista Brasileira de Educaçáa, n. 24, p. 40-52, set.- dez. 2003.

DAYRELL, J. T. A Escola "Faz" as Juventudes? Reflexôes em torno da socialização juvenil. Educaçáo e Sociedade, Campinas, v. 28, n. 100, p. 1105-1128, 2007.

DE CERTEAU, M. A invenção do cotidiano: artes de fazer. 3. ed. Petrópolis: Vozes, 1998.

FERREIRA, V. S.; RAIMUNDO, A.. conversas entre jovens: o uso youth-friendly de grupos focais. In: FERREIRA, V. S. (org). Pesquisar Jovens: caminhos e desafios metodológicos. Lisboa, Imprensa de Ciências Sociais, 2017, p. 57-89.

FONTENELE, I. A. Cultura do consumo: fundamentos e formas contemporâneas. Rio de Janeiro, FGV Editora, 2017.

GATTI, B. A. Grupo focal na pesquisa em Ciências Sociais e Humanas. Brasília: Liber Livro Editora Ltda, 2005.

GOMES, A. A. Apontamento sobre a pesquisa em educação: usos e possibilidades do grupo focal. Eccos. Revista Científica, v. 7, p. 275-290, 2006.

LAHIRE, B. Sucesso escolar nos meios populares: as razóes do improvável. Sáo Paulo: Ática, 1997.

MADEIRA, Z.; GOMES, D. D. O. Persistentes desigualdades raciais e resistências negras no Brasil contemporâneo. Serv. Soc. Soc., São Paulo, n. 133, p. 463479, set./dez. 2018. Disponível em <http://www.scielo.br/pdf/sssoc/n133/01016628-sssoc-133-0463.pdf>. Acesso em 30 de jul. 2019.

MARGULIS, M.; URRESTI, M.. La juventud es más que una palabra. Buenos Aires: Biblos, 2000, p. 85-101. 
OLIVEIRA, A. M.; TOMAZETTI, E. Quando a sociedade de consumidores vai à escola: um ensaio sobre a condição juvenil no Ensino Médio. Educar em Revista, Curitiba, n.44, p.181-200, jun. 2012. Disponível em: < http://www. scielo.br/pdf/er/n44/n44a12.pdf>. Acesso em 14 de mai. 2018.

PAIS, J. M. Culturas juvenis. Lisboa: Imprensa Nacional - Casa da Moeda, 2003.

SARLO. B. Cenas da vida pós moderna: intelectuais, arte, videocultura na Argentina. Rio de Janeiro, Editora UFRJ, 2013.

SCHWERTNER, S. F; FISCHER, R. M. B. Juventudes, conectividades múltiplas e novas temporalidades. Educação em Revista, v.28, n.01, p.395-420, 2012.

SOUZA, P. H. O.; LIMA, M. J. G. S. Estranhos no ninho: juventude, consumo e escola. e-Mosaicos, v. 7, p. 33-48, 2018. 